\title{
Avaliação do índice de temperatura de globo negro e umidade e desempenho de suínos nas fases de crescimento e terminação criados em sistemas em camas sobrepostas em condições de verão
}

\author{
Ilda de Fátima Ferreira Tinôco ${ }^{1}$, Cecília de Fátima Souza ${ }^{2}$, Paulo Armando Victoria de \\ Oliveira $^{3}$, Robson Mendes de Paulo ${ }^{4}$, Josiane Aparecida Campos ${ }^{5}$, Cinara da Cunha Siqueira \\ Carvalho $^{5}$, Marcelo Bastos Cordeiro ${ }^{5}$
}

\footnotetext{
${ }^{1}$ Departamento de Engenharia Agrícola - UFV. Bolsista do CNPq.

2 Departamento de Engenharia Agrícola - UFV.

${ }^{3}$ EMBRAPA/CNPSA (Centro Nacional de Pesquisa se Suínos e Aves), Concórdia, SCS.

${ }^{4}$ Mestre em Engenharia Agrícola - DEA/UFV.

${ }^{5}$ Doutorando do Departamento de Engenharia Agrícola - UFV.
}

RESUMO - Um estudo foi realizado com o objetivo de avaliar o sistema de criação em camas sobrepostas de maravalha e de casca de arroz, em comparação ao piso tradicional de concreto e sua influência no desempenho dos animais com base no ITGU (Índice de Temperatura de Globo negro e Umidade), no ganho de peso, no consumo de ração, na conversão alimentar e no consumo de água de suínos durante as fases de crescimento e terminação. Foram utilizados 216 animais (Landrace $\times$ Large White) divididos em 12 lotes uniformes, cada um com 18 animais, abrigados em 12 baias independentes, de modo que cada conjunto de quatro baias foi mantido em sistema de criação diferenciado. O experimento foi conduzido em blocos inteiramente casualizados com quatro repetições por sistema de criação. Verificou-se discreta vantagem do piso de concreto quanto ao ganho de peso, ao consumo de ração, à conversão alimentar e ao consumo de água. Portanto, o desempenho zootécnico não foi influenciado pelos sistemas de criação, embora os animais mantidos no piso de concreto tenham apresentado resultados ligeiramente melhores que os alojados em cama sobreposta. As camas constituem opção satisfatória para economia total de água de limpeza de pisos de concreto e para se evitar o lançamento de águas residuárias nos cursos d’água.

Palavras-chave: conforto térmico, ambiência animal, produção de suínos

\section{Evaluation of index of temperature of black globe and humidity and behavior of swine in the growth and termination phases reared on beds in summer conditions}

\begin{abstract}
A study was carried out with the objectives to evaluate the raising system deep-bedding (wood shavings and rice husk), in comparison to the traditional concrete floor in the raising of swine during the growth and finishing phases and to evaluate the animal performance based on BGTHI (Black Globe Temperature and Humidity Index), in the weight gain, ration intake, feed conversion and the water consumption. A total of 216 animals (Landrace $\times$ Large White) was used, divided in 12 uniform lots, each one with 18 animals, sheltered in 12 independent pens, in way that each set of four pens was kept in differentiated raising system. The experiment was conducted using complete randomized block design with four replications per raising system. A discrete advantage of concrete floor for weight gain, ration intake, feed conversion and the water consumption was observed.Therefore, the animal performance was not influenced by the raising systems, even so the animals kept in the concrete floor has showed resulted slightly better that the lodged deep- bedding. The beds appear as satisfactory option to provide total cleanness water economy of concrete floor and to prevent the discharge of residual water in the water courses.
\end{abstract}

Key Words: environmental comfort, animal environment, swine production

\section{Introdução}

No Brasil, o setor de produção animal tem alcançado grande desenvolvimento nos últimos anos. Constantes inovações nas áreas da genética, nutrição, manejo e sanidade estão sendo introduzidas (Tinoco, 2002). Um desafio na suinocultura brasileira é proporcionar aos animais bem-estar e conforto térmico associados à preservação ambiental, aspectos valorizados especialmente pelo consumidor europeu. 
O uso de camas sobrepostas no piso como alternativa ao tradicional piso de concreto tem se tornando comum na criação de suínos nas fases de crescimento e terminação, pois evita a utilização de lagoas para tratamento de dejetos, além de proporcionar melhor qualidade ambiental para os animais (Corrêa et al., 2000). O material de cama, geralmente orgânico, altera as características de dureza do piso e evita a umidade, o frio e a aderência dos dejetos facilitando sua remoção ao final de cada ciclo de criação (Lancini, 1986). Os materiais mais utilizados como cama são a maravalha e a casca de arroz.

Lay et al. (2001) observaram que suínos terminados em sistema de cama apresentaram menos comportamentos anormais, brincaram mais e tiveram menos lesões nas pernas que os terminados em sistema de confinamento sem cama. Machado Filho et al. (2001) observaram que a presença de palha na baia de suínos de dez semanas de idade provocou redução no comportamento de fuçar e morder os companheiros de baia.

A água também é um nutriente essencial para os suínos. De acordo com Tumelero (1998), o consumo de água por suínos em crescimento e terminação é de aproximadamente 5,5 L/animal/dia e a produção de urina, de 2,0 a 2,5\% do peso vivo. Silva (1973) sugeriu que a quantidade de água gasta na higienização das baias varia de 5 a $10 \mathrm{~L} /$ animal/dia.

Os suínos são animais que, em decorrência de suas características fisiológicas, têm seu desempenho reduzido quando expostos a condições de calor excessivo. Na Região Sul do Brasil, grande produtora de carne suína, em boa parte do ano, as condições climáticas são favoráveis à ambientação de edificações para suínos.

Este trabalho foi conduzido com o objetivo de avaliar o sistema de criação com camas sobrepostas de maravalha e de casca de arroz em comparação ao piso tradicional de concreto para suínos durante as fases de crescimento e terminação e em condições de verão. A comparação entre os sistemas foi realizada com base no Índice de Temperatura de Globo Negro e Umidade (ITGU) e os índices zootécnicos foram avaliados a partir da análise do ganho de peso, do consumo de ração, da conversão alimentar e do consumo de água pelos animais.

\section{Material e Métodos}

A pesquisa foi conduzida no período de 5 de dezembro de 2002 a 11 de abril de 2003, no verão, caracterizado por temperaturas médias máximas diárias de 29 a $31^{\circ} \mathrm{C}$. Janeiro e fevereiro são os meses mais quentes, com chuvas regulares e bem distribuídas, sem estação seca definida, verões quentes e precipitações totais anuais acima de $1.500 \mathrm{~mm}$.
As edificações utilizadas para realização do experimento foram três prédios com dimensões e características construtivas idênticas, pé direito de 3,25 m, pilares e treliças em aço galvanizado e cobertura com telhas de fibrocimento, inclinação de $15 \%$, beiral de 1,5 m elanternim. Os fechamentos laterais com 1,0 m de altura foram constituídos de placas vazadas de concreto e grades de ferro. As instalações foram distanciadas $10 \mathrm{~m}$ entre si, com orientação norte-sul. Cada prédio possuía área total de $120 \mathrm{~m}^{2}(12,0 \times 10,0 \mathrm{~m})$, dividida em quatro baias de $30 \mathrm{~m}^{2}(5,0 \times 6,0 \mathrm{~m})$ com toda área em torno das instalações gramada.

Nos prédios 1 e 2, foram utilizadas as camas de maravalha e de casca de arroz, respectivamente, e no terceiro prédio o piso convencional de concreto. A limpeza do sistema de baia com piso de concreto foi feita três vezes por semana. Na parte concretada das baias, foram instalados um bebedouro e um comedouro que permitia ao animal ingerir a ração úmida ou seca.

No experimento foram utilizados 216 animais (machos castrados e fêmeas) provenientes das granjas EMBRAPA, filhos de cruzamento de fêmeas F1 (Landrace $\times$ Large White), previamente separados em lotes uniformes de 72 animais por sistema de criação. Cada uma das instalações foi dividida em quatro boxes (baias), cada um com 18 animais nas fases de crescimento e terminação, com peso médio inicial de 25 kg e 63 dias de idade, em uma área média útil de $1,4 \mathrm{~m}^{2}$ por animal. Os animais receberam idêntico manejo e tratamento alimentar.

Para caracterização do ambiente térmico, foram medidas as temperaturas de globo negro, bulbo seco e bulbo úmido e a velocidade do ar no interior das instalações. As medições foram feitas durante todo o período experimental, a uma altura média de 0,40 m em relação ao piso, utilizando-se um sistema automático de aquisição de dados programado para armazenar as leituras dos sensores a cada intervalo de 10 minutos.

Os dados climáticos referentes ao ambiente externo às instalações foram obtidos por meio de uma estação meteorológica automática, localizada a $100 \mathrm{~m}$ da área onde foi montado o experimento. Com os dados de temperatura de globo negro, de bulbo seco e de bulbo úmido e de velocidade do ar, foram calculados o Índice de Temperatura de Globo Negro e Umidade (ITGU) e a Umidade Relativa do ar ambiente (UR).

Pelo Índice de Temperatura de Globo Negro e Umidade (ITGU) proposto por Buffington et al. (1977), a partir do índice de temperatura e umidade (ITU) desenvolvido por Thom (1958), são considerados em um único valor os efeitos da temperatura de bulbo seco, da umidade relativa, da radiação e da velocidade do ar. Esse índice, que tem sido 
usado para avaliar as condições de conforto animal em condições de clima tropical, é calculado por meio da seguinte equação:

$$
\mathrm{ITGU}=\mathrm{Tgn}+0,36 \cdot \mathrm{Tpo}-330,08
$$

em que Tgn = temperatura de globo negro, em Kelvin (K); e Tpo = temperatura do ponto de orvalho, em Kelvin (K).

Os estudos foram feitos considerando as médias horárias do dia, durante cada fase do período experimental: fase 1 = 63 aos 98 dias de idade dos animais ( 25 aos $50 \mathrm{~kg}$ ); fase $2=$ 98 aos 126 dias de idade ( 50 aos $75 \mathrm{~kg}$ ); e fase $3=126$ aos 183 dias de idade dos animais (75 aos $135 \mathrm{~kg}$ ).

Para avaliar o desempenho dos animais, foram registrados o ganho de peso (GP), o consumo de ração (CR), a conversão alimentar (CA) e o consumo médio de água (CAg), medido em cada instalação utilizando-se dois hidrômetros instalados em todas as baias de cada tratamento.

O experimento foi dividido em três fases, intermediadas por quatro pesagens, uma no início, à entrada dos animais nas instalações; duas intermediárias, no final da fase 1 e no final da fase 2; e uma final, antecedendo o abate dos animais. O fornecimento de ração foi ad libitum, com pesagem das sobras sempre ao término de cada fase.

Para avaliação do ambiente térmico, o experimento foi montado segundo esquema de parcelas subdivididas, no qual as parcelas foram compostas dos sistemas de criação (cama de maravalha, cama de casca de arroz e piso de concreto) e as subparcelas, dos horários (de 1 a 24 horas), em delineamento em blocos casualizados (dias experimentais), com 35 repetições para a fase 1,27 repetições para fase 2 e 56 repetições para fase 4 .

Na avaliação do desempenho produtivo dos animais, o experimento foi montado em delineamento inteiramente casualizado, em esquema de parcelas subdivididas, em que os três sistemas de criação corresponderam às parcelas e as três fases de observação, às subparcelas, com quatro repetições (baias de criação).

O ambiente térmico foi avaliado por meio do índice térmico ambiental: Índice de Temperatura de Globo Negro e Umidade. Para o ITGU, considerando a finalidade específica do estudo, independentemente de a interação fase $\times$ horário $\times$ tratamento ser significativa, optou-se pelo seu desdobramento.

Os dados foram interpretados por meio de análises de variância e de regressão. As médias do fator qualitativo foram comparadas pelo teste Tukey. Para o fator quantitativo, foi utilizada a técnica de regressão, empregando-se o teste $t$ de Student no coeficiente de determinação e no fenômeno.

\section{Resultados e Discussão}

A fase, o horário e suas interações influenciaram significativamente o ITGU (Tabela 1). A interação dupla significativa indica que as duas variáveis agem em conjunto sobre o valor do ITGU.

Os sistemas de criação cama de maravalha e cama de casca de arroz resultaram em valores de ITGU significantes em todos os horários em todas as fases (Tabela 1). Na fase 1, de 9 às 11 h e de 18 às 20 h, o sistema de criação em piso de concreto resultou em menores valores de ITGU. Na fase 3, os maiores valores de ITGU ocorreram no sistema de criação em piso de concreto, entre 12 e 13 h. Verificou-se ainda que, na fase 2 , ocorreram os maiores valores do ITGU e, na fase 3, os menores, o que está relacionado à cadência média diária da temperatura ambiental. Em pesquisa realizada por Turco (1997), o limite superior de conforto térmico para suínos em terminação, com base no ITGU, é igual a 72. Nos sistemas de criação avaliados, nas horas mais quentes do dia os animais apresentavam ofegação acelerada e constante, evidenciando possível desconforto térmico. Esse comportamento foi observado com mais freqüência nos sistemas de criação com camas sobrepostas.

Nas fases 1 e 2, o ganho de peso não diferiu $(\mathrm{P}<0,05)$ entre os sistemas de criação cama de maravalha (TM) e de casca de arroz (TA), entretanto, os valores diferiram $(\mathrm{P}<0,05)$ dos obtidos no sistema de piso de concreto (TC), no qual o ganho de peso dos animais foi maior. O ganho de peso não foi influenciado pelos sistemas de criação cama de maravalha e cama de casca de arroz, mas foi afetado pelo sistema piso de concreto, no qual o ganho foi maior. Na fase 3, o sistema de criação piso de concreto promoveu os maiores valores médios de ganho de peso, que não diferiram dos valores obtidos nos sistemas de camas sobrepostas. No sistema de criação piso de concreto, o ganho de peso decresceu da fase 1 para a fase 2 e aumentou novamente na fase 3 , quando atingiu os maiores valores. Nos sistemas de criação cama de maravalha e cama de casca de arroz, as fases 1 e 2 foram similares e diferiram $(\mathrm{P}<0,05)$ da fase 3 , quando se observou o maior ganho de peso.

O maior ganho de peso médio diário obtido na fase 3 (Tabela 3) possivelmente foi ocasionado pelo fato de que, neste período, a temperatura média interna manteve-se abaixo da média externa, o que possibilitou melhor condição de conforto térmico aos animais. Nas fases 1 e 2, a temperatura média interna manteve-se acima da temperatura média externa, indicando que os animais estavam em desconforto térmico e, conseqüentemente, seu desempenho produtivo sofreu influência negativa. 
Tabela 1 - Valores médios horários do ITGU para os sistemas de criação em cama sobreposta de maravalha e casca de arroz, e piso de concreto, nas fases 1, 2 e 3

Table 1 - Time average values of ITGU for different raising systems with wood shavings and rice husks deep-bedding, and concrete floors, in the phases 1,2 and 3

\begin{tabular}{|c|c|c|c|c|c|c|c|c|c|}
\hline \multirow[t]{3}{*}{$\begin{array}{l}\text { Hora } \\
\text { Time }\end{array}$} & \multicolumn{3}{|c|}{$\begin{array}{l}\text { Fase } 1 \\
\text { Phase } 1\end{array}$} & \multicolumn{3}{|c|}{$\begin{array}{l}\text { Fase2 } \\
\text { Phase } 2\end{array}$} & \multicolumn{3}{|c|}{$\begin{array}{l}\text { Fase3 } \\
\text { Phase } 3\end{array}$} \\
\hline & \multicolumn{2}{|c|}{$\begin{array}{l}\text { Cama sobreposta } \\
\text { Deep-bedding }\end{array}$} & \multirow[t]{2}{*}{$\begin{array}{l}\text { Piso de concreto } \\
\text { Concrete floor }\end{array}$} & \multicolumn{2}{|c|}{$\begin{array}{c}\text { Cama sobreposta } \\
\text { Deep-bedding }\end{array}$} & \multirow[t]{2}{*}{$\begin{array}{l}\text { Piso de concretc } \\
\text { Concrete floor }\end{array}$} & \multicolumn{2}{|c|}{$\begin{array}{c}\text { Cama sobreposta } \\
\text { Deep-bedding }\end{array}$} & \multirow[t]{2}{*}{$\begin{array}{l}\text { so de concretc } \\
\text { Concretefloor }\end{array}$} \\
\hline & $\begin{array}{c}\text { Maravalha } \\
\text { Wood shavings }\end{array}$ & $\begin{array}{l}\text { Casca de } \\
\text { arroz } \\
\text { Rice husks }\end{array}$ & & $\begin{array}{l}\text { Maravalha } \\
\text { Wood shavings }\end{array}$ & $\begin{array}{l}\text { Casca de } \\
\text { arroz } \\
\text { Rice husks }\end{array}$ & & $\begin{array}{l}\text { Maravalha } \\
\text { Wood shavings }\end{array}$ & $\begin{array}{l}\text { Casca de } \\
\text { arroz } \\
\text { Rice husks }\end{array}$ & \\
\hline 00:00 & $72,5 a$ & $72,8 \mathrm{a}$ & $71,1 \mathrm{a}$ & $72,7 \mathrm{a}$ & $73,7 \mathrm{a}$ & $72,8 \mathrm{a}$ & $71,2 \mathrm{a}$ & $70,2 \mathrm{a}$ & $70,9 a$ \\
\hline 01:00 & $71,4 a$ & $71,5 a$ & $70,3 a$ & $72,0 \mathrm{a}$ & $72,5 a$ & $72,5 a$ & $70,7 a$ & $69,6 a$ & $70,2 \mathrm{a}$ \\
\hline 02:00 & $70,5 a$ & $70,2 \mathrm{a}$ & $69,8 a$ & $71,2 \mathrm{a}$ & $71,9 a$ & $71,8 \mathrm{a}$ & $70,2 \mathrm{a}$ & $69,0 \mathrm{a}$ & $69,7 a$ \\
\hline 03:00 & $69,7 a$ & $70,0 \mathrm{a}$ & $69,2 \mathrm{a}$ & $70,6 a$ & $71,2 \mathrm{a}$ & $71,1 \mathrm{a}$ & $69,7 \mathrm{a}$ & $68,5 a$ & $69,1 \mathrm{a}$ \\
\hline 04:00 & $69,2 \mathrm{a}$ & $69,4 a$ & $68,7 \mathrm{a}$ & $69,9 a$ & $70,6 a$ & $70,5 a$ & $69,3 a$ & $68,1 \mathrm{a}$ & $68,7 a$ \\
\hline 05:00 & $68,7 a$ & $69,0 \mathrm{a}$ & $68,3 \mathrm{a}$ & $69,3 a$ & $70,0 \mathrm{a}$ & $69,9 a$ & $69,0 \mathrm{a}$ & $67,8 \mathrm{a}$ & 68,3 a \\
\hline 06:00 & $68,6 a$ & $68,7 a$ & $67,9 \mathrm{a}$ & $68,8 a$ & $69,6 a$ & $69,4 a$ & $68,7 a$ & $67,6 a$ & $68,0 \mathrm{a}$ \\
\hline 07:00 & $69,7 \mathrm{a}$ & $69,2 \mathrm{a}$ & $67,9 a$ & $68,6 a$ & $69,3 a$ & $69,2 \mathrm{a}$ & $68,9 a$ & $67,5 a$ & $68,2 \mathrm{a}$ \\
\hline 08:00 & $71,2 \mathrm{a}$ & $71,0 \mathrm{a}$ & $69,1 \mathrm{a}$ & $70,2 \mathrm{a}$ & $70,2 \mathrm{a}$ & $70,6 a$ & $69,7 \mathrm{a}$ & $68,0 \mathrm{a}$ & $69,2 \mathrm{a}$ \\
\hline 09:00 & $73,6 a$ & $73,2 \mathrm{a}$ & $70,9 b$ & $72,6 a$ & $72,5 a$ & $73,8 a$ & $70,8 a$ & $69,1 \mathrm{a}$ & $70,9 a$ \\
\hline $10: 00$ & $74,9 a$ & $74,5 \mathrm{a}$ & $72,1 b$ & $75,5 a$ & $74,8 a$ & $76,3 a$ & $71,9 a$ & $70,3 a$ & $72,4 a$ \\
\hline $11: 00$ & $75,8 a$ & $75,4 a$ & $73,5 b$ & $76,5 a$ & $75,9 a$ & $77,6 a$ & $73,3 a$ & $71,8 a$ & $74,0 \mathrm{a}$ \\
\hline $12: 00$ & $77,1 \mathrm{a}$ & $76,7 a$ & $75,2 \mathrm{a}$ & $77,5 \mathrm{a}$ & $77,0 \mathrm{a}$ & $78,8 a$ & $74,8 \mathrm{ab}$ & $73,4 b$ & $75,8 a$ \\
\hline $13: 00$ & $77,9 a$ & $77,9 a$ & $76,6 a$ & $78,4 a$ & $78,2 \mathrm{a}$ & $79,9 a$ & $76,2 \mathrm{ab}$ & $74,9 \mathrm{~b}$ & $77,2 \mathrm{a}$ \\
\hline $14: 00$ & $79,0 a$ & $79,1 \mathrm{a}$ & $78,1 \mathrm{a}$ & $79,3 a$ & $79,1 \mathrm{a}$ & $80,6 a$ & $77,1 \mathrm{a}$ & $76,0 \mathrm{a}$ & $78,1 \mathrm{a}$ \\
\hline $15: 00$ & $79,7 a$ & $79,9 a$ & $78,8 a$ & $80,2 \mathrm{a}$ & $80,0 a$ & $81,2 \mathrm{a}$ & $77,6 a$ & $76,8 a$ & $78,7 a$ \\
\hline $16: 00$ & $80,0 \mathrm{a}$ & $80,4 a$ & $78,9 a$ & $81,0 \mathrm{a}$ & $80,7 a$ & $81,7 a$ & $77,9 \mathrm{a}$ & $77,2 \mathrm{a}$ & 78,9 a \\
\hline $17: 00$ & $80,3 a$ & $80,7 a$ & $78,8 \mathrm{a}$ & $81,4 a$ & $81,0 \mathrm{a}$ & $81,6 a$ & $78,3 a$ & $77,5 \mathrm{a}$ & $78,8 \mathrm{a}$ \\
\hline $18: 00$ & $80,9 a$ & $81,4 a$ & $78,8 b$ & $81,2 \mathrm{a}$ & $81,0 \mathrm{a}$ & $81,2 \mathrm{a}$ & $77,9 a$ & $77,2 \mathrm{a}$ & $78,3 \mathrm{a}$ \\
\hline 19:00 & $81,8 \mathrm{a}$ & $81,9 a$ & $78,8 \mathrm{~b}$ & $82,2 \mathrm{a}$ & $81,7 a$ & $81,0 \mathrm{a}$ & $76,7 a$ & $76,0 \mathrm{a}$ & $76,8 \mathrm{a}$ \\
\hline 20:00 & $79,7 a$ & $80,2 a$ & $77,4 \mathrm{~b}$ & $80,4 a$ & $80,5 a$ & $80,0 \mathrm{a}$ & $75,1 \mathrm{a}$ & $74,3 a$ & $75,1 \mathrm{a}$ \\
\hline 21:00 & $76,9 a$ & $77,5 \mathrm{a}$ & $75,2 \mathrm{a}$ & $77,7 a$ & $78,1 \mathrm{a}$ & $77,6 a$ & $73,7 a$ & $72,9 a$ & $73,6 a$ \\
\hline $22: 00$ & $74,8 \mathrm{a}$ & $75,3 a$ & $73,4 a$ & $75,3 a$ & $76,0 \mathrm{a}$ & $75,6 a$ & $72,7 \mathrm{a}$ & $71,2 \mathrm{a}$ & $72,5 a$ \\
\hline 23:00 & $73,3 a$ & $73,8 \mathrm{a}$ & $72,1 \mathrm{a}$ & $73,6 a$ & $74,3 a$ & $74,1 \mathrm{a}$ & $71,8 \mathrm{a}$ & $70,8 a$ & $71,6 a$ \\
\hline
\end{tabular}

Médias seguidas de letras diferentes na linha, para cada fase, diferem $(P<0,05)$ pelo teste Tukey.

Means followed by different letters within a row, for each phase, differ $(P<0.05)$ by Tukey test.

Tabela 2 - Ganho de peso, de suínos em terminação, nos sistemas de criação em cama de maravalha, cama de casca de arroz ou piso de concreto em três fases de desenvolvimento

Table 2 - Weight gain of swine in the finishing phase, in the raising systems in wood shaving litter-bed, rice husk litter-bed and concrete floor in three phases of development

\begin{tabular}{|c|c|c|c|c|}
\hline \multirow[t]{4}{*}{$\begin{array}{l}\text { Fase } \\
\text { Phase }\end{array}$} & \multicolumn{3}{|c|}{$\begin{array}{l}\text { Sistemas de criação } \\
\text { Raising system }\end{array}$} & \multirow[t]{3}{*}{$\begin{array}{r}\text { Total } \\
(\mathrm{kg})\end{array}$} \\
\hline & \multicolumn{2}{|c|}{$\begin{array}{c}\text { Cama sobreposta } \\
\text { Deep-bedding }\end{array}$} & \multirow[t]{2}{*}{$\begin{array}{l}\text { Piso de concreto } \\
\text { Concrete floor }\end{array}$} & \\
\hline & \multirow[t]{2}{*}{$\begin{array}{c}\text { Maravalha } \\
\text { Wood shavings }\end{array}$} & $\begin{array}{c}\text { Casca de arroz } \\
\text { Rice husk }\end{array}$ & & \\
\hline & & \multicolumn{2}{|c|}{ kg/dia } & \\
\hline 1 & $0,655 \mathrm{Bb}$ & $0,675 \mathrm{Bb}$ & 0,819Aab & 23,3 \\
\hline 2 & $0,650 \mathrm{Bb}$ & $0,607 \mathrm{Bb}$ & 0,763Ab & 18,9 \\
\hline 3 & 0,863Aa & 0,839Aa & 0,891Аa & 49,4 \\
\hline
\end{tabular}

Médias seguidas de letras diferentes na linha (maiúscula) ou na coluna (minúscula), para cada fase, diferem $(P<0,05)$ pelo teste Tukey.

Means followed by different letters within a row (capital) or a column (small), for each phase, differ $(P<0.05)$ by Tukey test.
Os animais mantidos no piso de concreto provavelmente foram privilegiados pelo manejo de limpeza (lavagem com água) das baias 2 a 3 vezes por semana, o que pode ter influenciado seu desempenho. Essa prática reduz a temperatura corporal desses animais, o que não ocorreu com aqueles mantidos nos sistemas com camas. No entanto, em termos de umidade relativa, não foram observadas diferenças significativas.

O consumo médio diário de ração não diferiu entre os sistemas de criação nas fases de 25 a 50 kg e de 50 a 75 kg (Tabela 3). Na fase 3 (75 a 135 kg), o consumo de ração pelos animais criados em piso de concreto foi semelhante ao daqueles mantidos em cama de maravalha. Entre os animais mantidos nas camas de maravalha e de casca de arroz, não houve diferenças para o consumo médio diário de ração.

O comportamento para o consumo de ração pelos animais ao longo do período experimental foi similar ao do 
Tabela 3 - Consumo de ração por suínos em terminação nos sistemas de criação em cama de maravalha, cama de casca de arroz ou piso de concreto em três fases de desenvolvimento

Table 3 - Feed intake of swine in the finishing phase, in the raising systems in wood shaving litter-bed, rice husk litter-bed and concrete floor in three phases of development

\begin{tabular}{|c|c|c|c|}
\hline \multirow[t]{3}{*}{$\begin{array}{l}\text { Fase } \\
\text { Phase }\end{array}$} & \multicolumn{3}{|c|}{$\begin{array}{l}\text { Sistemas de criação } \\
\text { Raising system }\end{array}$} \\
\hline & \multicolumn{2}{|c|}{$\begin{array}{c}\text { Cama sobreposta } \\
\text { Deep-bedding }\end{array}$} & \multirow[t]{2}{*}{$\begin{array}{l}\text { Piso de concreto } \\
\text { Concrete floor }\end{array}$} \\
\hline & $\begin{array}{l}\text { Maravalha } \\
\text { Wood shavings }\end{array}$ & $\begin{array}{c}\text { Casca de arroz } \\
\text { Rice husk }\end{array}$ & \\
\hline 1 & $1,360 \mathrm{Ac}$ & $1,558 \mathrm{Ab}$ & $1,468 \mathrm{Ac}$ \\
\hline 2 & $1,890 \mathrm{Ab}$ & $1,770 \mathrm{Ab}$ & $1,925 \mathrm{Ab}$ \\
\hline 3 & 2,503Aba & $2,443 \mathrm{Ba}$ & $2,745 \mathrm{Aa}$ \\
\hline
\end{tabular}

Médias seguidas de letras diferentes na linha (maiúscula) ou na coluna (minúscula), para cada fase, diferem $(P<0,05)$ pelo teste Tukey.

Means followed by differentletters within a row (capital) or a column (small), for each phase, differ $(P<0.05)$ by Tukey test.

consumo de ração (Figura 1), que, em todas as fases, foi menor consumo nos animais mantidos no sistema de criação cama de maravalha e maior naqueles do sistema de criação de piso de concreto.

A condição de bem-estar do animal afeta o consumo de alimentos. De acordo com Baêta \& Souza (1997), sob estresse calórico, os animais normalmente reduzem a ingestão alimentar na tentativa de minimizar o aumento do calor corporal. Nesta pesquisa, os animais criados no sistema de cama de maravalha foram submetidos a essa condição.

Os valores de conversão alimentar não diferiram entre os sistemas de criação (Tabela 4), o que está de acordo com o observado por Oliveira (1999b), que, estudando o desem-

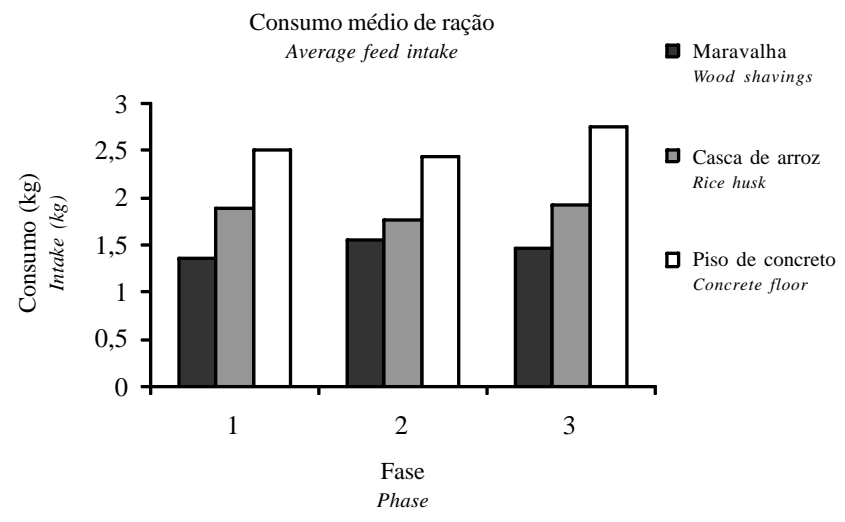

Figura 1 - Consumo de ração de suínos em terminação nos sistemas de criação em cama de maravalha, cama de casca de arroz ou piso de concreto em três fases de desenvolvimento.

Figure 1 - Feed intake, of swine in the finishing phase, in the raising systems in wood shaving litter-bed, rice husk litter-bed and concrete floor in three phases of development.
Tabela 4 - Conversão alimentar de suínos em terminação, nos sistemas de criação em cama de maravalha, cama de casca de arroz ou piso de concreto

Table 4 - Feed/gain ratio of swine in the finishing phase, in the raising systems in wood shaving litter-bed, rice husk litter-bed and concrete floor

\begin{tabular}{llc}
\hline $\begin{array}{l}\text { Sistema de criação } \\
\text { Raising system }\end{array}$ & $\begin{array}{c}\text { Média } \\
\text { Mean }\end{array}$ \\
\hline $\begin{array}{l}\text { Cama sobreposta } \\
\text { Deep-bedding }\end{array}$ & $\begin{array}{l}\text { Maravalha } \\
\text { Wood shavings } \\
\text { Casca de arroz } \\
\text { Rice husk }\end{array}$ & $1,912 \mathrm{~A}$ \\
$\begin{array}{l}\text { Piso de concreto } \\
\text { Concrete floor }\end{array}$ & $1,923 \mathrm{~A}$ \\
\hline
\end{tabular}

Médias seguidas de letras diferentes na linha (maiúscula) ou na coluna (minúscula), para cada fase, diferem $(P<0,05)$ pelo teste Tukey. Means followed by different letters within a row (capital) or a column (small), for each phase, differ $(P<0.05)$ by Tukey test.

penho zootécnico de suínos criados em piso ripado e sobre cama de maravalha, não encontrou diferença entre os sistemas.

A combinação de altos valores de temperatura e umidade relativa pode reduzir a quantidade de calor dissipado na forma latente. Com essa redução, diminui o consumo de ração e aumenta a freqüência respiratória e a temperatura retal dos animais (Machado, 1985). É possível que o desempenho produtivo dos suínos na fase 2 tenha sido influenciado negativamente pela variação da alta umidade relativa, o que ocasionou redução da habilidade em dissipar calor corporal para o ambiente, em decorrência das dificuldades para a vaporização da água no nível da pele, uma vez que o processo exige troca de calor. Apesar de os valores da carga térmica radiante incidente no sistema de piso de concreto terem sido relativamente elevados, o desempenho dos animais não foi prejudicado, provavelmente em virtude do manejo adotado na limpeza das baias, que reduziu as temperaturas de piso, de pele dos animais e de paredes.

A água deve ser ministrada em qualidade e quantidade suficientes para sobrevivência dos suínos e, quando é oferecida em temperatura adequada, auxilia também na regulação da temperatura corporal dos animais.

Na fase 1 (63 a 98 dias de vida), o consumo de água (Tabela 5) pelos animais mantidos no sistema de criação de cama de maravalha foi semelhante ao daqueles mantidos no sistema de criação de cama de casca de arroz, que foi igual ao daqueles criados no sistema de piso de concreto. Nas fases 2 e 3, não houve diferença entre os sistemas de criação, no entanto, os valores observados mantiveram-se nos limites citados por Bodman (1994). Segundo esse autor, o consumo de água por suínos de 25 a 50 kg (crescimento) e de 50 a 100 kg (terminação) é, respectivamente, de 4 a 7 e de 5 a 10 L/animal/dia. 
Tabela 5 - Consumo de água por suínos em terminação nos sistemas de criação em cama de maravalha, cama de casca de arroz ou piso de concreto em três fases de desenvolvimento

Table 5 - Water intake of swine in the finishing phase, in the raising systems in wood shaving litter-bed, rice husk litter-bed and concrete floor in three phases of development

\begin{tabular}{|c|c|c|c|}
\hline \multirow[t]{3}{*}{$\begin{array}{l}\text { Fase } \\
\text { Phase }\end{array}$} & \multicolumn{3}{|c|}{$\begin{array}{l}\text { Sistemas de criação } \\
\text { Raising system }\end{array}$} \\
\hline & \multicolumn{2}{|c|}{$\begin{array}{c}\text { Cama sobreposta } \\
\text { Deep-bedding }\end{array}$} & \multirow[t]{2}{*}{$\begin{array}{l}\text { Piso de concreto } \\
\text { Concrete floor }\end{array}$} \\
\hline & $\begin{array}{l}\text { Maravalha } \\
\text { Wood shavings }\end{array}$ & $\begin{array}{l}\text { Casca de arroz } \\
\text { Rice husk }\end{array}$ & \\
\hline 1 & $4,675 \mathrm{Bb}$ & $6,050 \mathrm{ABb}$ & $6,825 \mathrm{Aa}$ \\
\hline 2 & 7,725Aa & 7,225Aab & 7,600Aa \\
\hline 3 & $8,225 \mathrm{Aa}$ & 7,775Aa & 7,500Aa \\
\hline
\end{tabular}

Médias seguidas de letras diferentes na linha (maiúscula) ou na coluna (minúscula), para cada fase, diferem $(P<0,05)$ pelo teste Tukey. Means followed by different letters within a row(capital) or a column (small), for each phase, differ $(P<0.05)$ by Tukey test.

\section{Conclusões}

O índice de temperatura de globo e tmidade é melhor nos sistemas de criação em cama de casca de arroz e em piso de concreto, que possui discreta vantagem em comparação aos de cama sobreposta.

Os sistemas de criação em cama sobreposta e em piso de concreto não influenciam o ganho de peso, o consumo de ração, a conversão alimentar e o consumo de água. Animais mantidos no piso de concreto apresentam desempenho ligeiramente melhor que o daqueles alojados em camas sobrepostas.

Apesar da ligeira vantagem, não-significativa, do sistema de criação em piso de concreto, os sistemas em camas sobrepostas constituem opções também satisfatórias e voltadas à conservação ambiental. A cama de casca de arroz é a mais indicada em comparação à de maravalha.

\section{Literatura Citada}

BAÊTA, F.C.; SOUZA, C.F. Ambiência em edificações rurais: conforto animal. Viçosa, MG: Editora UFV, 1997. 246p.

BODMAN, G.R. Evaluation of housing and environmental adequacy: principles and concepts. Lincoln: Cooperative Extension at the University of Nebrasca, 1994. 28p.
BUFFINGTON, C.S.; COLLAZO-AROCHO, A.; CANTON, G.H. et al. Black globe humidity index (BGHI) as comfort equation for dairy cows. St. Joseph: American Society Agricultural Engineers, 1977. 19p. (Paper, 77-4517).

CORREA, E.K.; PERDOMO, C.C.; JACONDINO, I.F.R. et al. Condicionamento ambiental e desempenho de suínos em crescimento e terminação criados sobre piso com leito de cama. Revista Brasileira de Zootecnia, v.29, n.6, p.2072-2079, 2000.

LANCINI, J.B. Aspectos gerais sobre a intoxicação e contaminação através da cama aviária. Avicultura Industrial, v.76, n.923, p.32-34, 1986

LAY, D. C. JR.; HAUSSMANN, M. F.; DANIELS, M. J. Hoop housing for feeder pigs offers a welfare-friendly environment compared to a nonbedded confinement system. Journal of Applied Animal Welfare Science, v.3, n.1, p.33-48, 2000.

MACHADO, L.C.P. Instalações para suínos. Suinocultura Industrial, v.7, n.75, p.6-14, 1985

MACHADO FILHO, L.C.P.; SILVEIRA, M.C.A.C.; HÖTZEL, M.J. et al. Produção agroecológica de suínos: uma alternativa sustentável para a pequena propriedade. In: II CONFERÊNCIA INTERNACIONAL VIRTUAL SOBRE QUALIDADE DE CARNE SUÍNA, 05 de novembro a 06 de dezembro de 2001. Disponível em:<http://www.freewebs.com/hotzel/Suino\%20Organico\%20 2001.pdf> Acesso em: 23/08/2005.

OLIVEIRA, P.A.V. Qualidade do ambiente para a produção de leitões. Ambiência e qualidade na produção industrial de suínos. In: SILVA, I.J.O. (Ed.) Piracicaba: Fundação de Estudos Agrários Luiz de Queiroz, 1999b. 247p.

SILVA, P.R. Estudo das características dos resíduos das instalações de confinamento de suínos. In: CONGRESSO BRASILEIRO DE ENGENHARIA SANITÁRIA, 7., 1973, Salvador. Separata... São Carlos: EESC - USP, 1973. 18p.

THOM, E.C. Cooling degree-days: air conditioning, weating and ventilating. Transactions of the ASAE, v.55, n.7, p.65-72, 1958.

TINOCO, I.F.F.; FIGUEIREDO, J.L.A.; SANTOS, R.C et al. Avaliação de materiais alternativos utilizados na confecção de placas porosas para sistemas de resfriamento adiabático evaporativo. Revista Brasileira de Engenharia Agrícola e Ambiental, v.6, n.1, p.147-150, 2002.

TUMELERO, I.L. Avaliação de materiais para o sistema de criação de suínos sobre cama. Florianópolis: Universidade Federal de Santa Catarina, 1998. 84p. Dissertação (Mestrado em Zootecnia) - Universidade Federal de Santa Catarina, 1998.

TURCO, S.H.N. Análise de sistemas de acondicionamento térmico em maternidades para suínos. Viçosa, MG: Universidade Federal de Viçosa, 1997. 91p. Tese (Doutorado em Engenharia Agrícola) - Universidade Federal de Viçosa, 1997. 